\title{
Pepper Rootstock and Scion Physiological Responses Under Drought Stress
}

\author{
Lidia López-Serrano ${ }^{1}$, Guillermo Canet-Sanchis', Gabriela Vuletin Selak², \\ Consuelo Penella ${ }^{1}$, Alberto San Bautista ${ }^{3}$, Salvador López-Galarza ${ }^{3}$ and \\ Ángeles Calatayud ${ }^{1 *}$
}

\begin{abstract}
'Departamento de Horticultura, Instituto Valenciano de Investigaciones Agrarias, Valencia, Spain, ${ }^{2}$ Department of Plant Science, Institute for Adriatic Crops and Karst Reclamation, Split, Croatia, ${ }^{3}$ Departamento de Producción Vegetal, Universitat Politècnica de València, Valencia, Spain
\end{abstract}

\section{OPEN ACCESS}

Edited by: Claudio Bonghi,

University of Padova, Italy

Reviewed by:

Georgia Ntatsi,

Institute of Plant Breeding and Genetic Resources, Hellenic Agricultural Organisation (HAO),

Greece

Cherubino M. Leonardi, Università degli Studi di Catania, Italy

*Correspondence: Ángeles Calatayud calatayud_ang@gva.es

Specialty section: This article was submitted to Crop and Product Physiology,

a section of the journal

Frontiers in Plant Science

Received: 18 September 2018 Accepted: 10 January 2019 Published: 28 January 2019

Citation:

López-Serrano L,

Canet-Sanchis G, Vuletin Selak G, Penella C, San Bautista A

López-Galarza S and Calatayud Á (2019) Pepper Rootstock and Scion Physiological Responses Under Drought Stress.

Front. Plant Sci. 10:38. doi: 10.3389/fpls.2019.00038
In vegetables, tolerance to drought can be improved by grafting commercial varieties onto drought tolerant rootstocks. Grafting has emerged as a tool that copes with drought stress. In previous results, the A25 pepper rootstock accession showed good tolerance to drought in fruit production terms compared with non-grafted plants and other rootstocks. The aim of this work was to study if short-term exposure to drought in grafted plants using A25 as a rootstock would show tolerance to drought now. To fulfill this objective, some physiological processes involved in roots (rootstock) and leaves (scion) of grafted pepper plants were analyzed. Pepper plants not grafted (A), selfgrafted (A/A), and grafted onto a tolerant pepper rootstock A25 (A/A25) were grown under severe water stress induced by PEG addition $(-0.55 \mathrm{MPa})$ or under control conditions for 7 days in hydroponic pure solution. According to our results, water stress severity was alleviated by using the A25 rootstock in grafted plants (A/A25), which indicated that mechanisms stimulated by roots are essential to withstand stress. A A25 had a bigger root biomass compared with plants $A$ and AVA that resulted in better water absorption, water retention capacity and a sustained $\mathrm{CO}_{2}$ assimilation rate. Consequently, plants A/A25 had a better carbon balance, supported by greater nitrate reductase activity located mainly in leaves. In the non-grafted and self-grafted plants, the photosynthesis rate lowered due to stomatal closure, which limited transpiration. Consequently, part of $\mathrm{NO}_{3}{ }^{-}$uptake was reduced in roots. This condition limited water uptake and $\mathrm{CO}_{2}$ fixation in plants $\mathrm{A}$ and $\mathrm{A} / \mathrm{A}$ under drought stress, and accelerated oxidative damage by producing reactive oxygen species (ROS) and $\mathrm{H}_{2} \mathrm{O}_{2}$, which were highest in their leaves, indicating great sensitivity to drought stress and induced membrane lipid peroxidation. However, drought deleterious effects were slightly marked in plants A compared to A A. To conclude, the A25 rootstock protects the scion against oxidative stress, which is provoked by drought, and shows better $\mathrm{C}$ and $\mathrm{N}$ balances that enabled the biomass to be maintained under water stress for short-term exposure, with higher yields in the field.

\footnotetext{
Keywords: drought, gas exchange, grafted, oxidative stress, pepper, rootstock, water relations
} 


\section{INTRODUCTION}

In agriculture, drought stress is one of the most limiting factors for growing crops, mainly due to a poor plant carbon balance, which is largely dependent on photosynthesis (Flexas et al., 2009). This is associated with a significant drop in the leaf water potential and transpiration (Fahad et al., 2017) which, in turn, affect nutrient absorption. These restrictions make plants more susceptible to photo damage by increasing reactive oxygen species (ROS) that may damage the cellular membrane and other vital molecules like DNA, lipids, and proteins (Fahad et al., 2017). Metabolic alterations in plants by drought lead to significant yield reductions, which imply major economic loss and affect global food security. Bearing in mind that most climate change scenarios predict a more drought incidences, it is necessary to increase food production to satisfy the population's demand (Fahad et al., 2017).

The selection of tolerant genotypes is a considerable challenge to improve productivity with limited water resources. Conventional plant breeding has had limited success at mitigating the effects of abiotic stress on plant productivity (Gilliham et al., 2017; Lamaoui et al., 2018). This can be ascribed to both the complexity of traits and lack of appropriate selection tools (Ashraf and Foolad, 2007; Schwarz et al., 2010). In addition, it is very difficult to combine enhanced yields and superior product quality with tolerance to drought and other abiotic stresses (Finckh, 2008; Lammerts van Bueren et al., 2011).

Genetic transformation could prove a powerful tool in plant breeding (Borsani et al., 2003; Cuartero et al., 2006; MartínezRodríguez et al., 2008). However, lack of public acceptance of genetic engineering clearly indicates the need for alternative strategies to enhance abiotic stress tolerance (Munns, 2002; Estañ et al., 2005).

One possible solution to cope with abiotic stress and reduce production losses involves using graft technology (Rivero et al., 2003a; Colla et al., 2010; Savvas et al., 2010; Schwarz et al., 2010; Sánchez-Rodríguez et al., 2014). Some studies have demonstrated the efficiency of tolerant rootstocks in reducing the effects of drought on the scion by improving physiological performance and productivity through different approaches, like using a larger and vigorous root rootstock system capable of absorbing water and nutrients, and maintaining the root relative growth rate and leaf-relative water content more efficiently than non-grafted plants. This behavior has been observed in tomato (SánchezRodríguez et al., 2012; Yao et al., 2016) and watermelon (Chouka and Jebari, 1999; Alan et al., 2007; Rouphael et al., 2008). Another alternative is active osmotic adjustment as it can contribute to improve the uptake of more water mediated by the accumulation of a range of osmotically active molecules, as reported in pepper (Anjum et al., 2012; Penella et al., 2014b) and tomato (Yao et al., 2016) grafted plants. In addition, plants subjected to drought stress tend to overproduce ROS; the activation and/or modulation of an antioxidant defense system plays an important role in conferring tolerance under drought and constitutes the first line of defense by reducing damage by lipid peroxidation in tomato grafted plants (Yao et al., 2016). The ability to limit water loss can help to maintain the photosynthesis rate and improve $\mathrm{NO}_{3}{ }^{-}$assimilation in grafted plants under water deficit by allowing both plant growth and productivity (Rouphael et al., 2008; Sánchez-Rodríguez et al., 2013; Penella et al., 2014b).

Recently, the number of reports on grafting as a mean to improve tolerance to drought has increased in mainly tomato, watermelon and cucumber (Kumar et al., 2017). Nevertheless, the use of rootstocks that tolerate abiotic stresses is lacking in pepper plants because available commercial rootstocks provide limited profits (Lee et al., 2010; Penella et al., 2014a; Kyriacou et al., 2017). Overall screenings to detect tolerant Capsicum plants are necessary to use them as rootstocks (Penella et al., 2014a).

In our previous experiments, after wide screening of Capsicum accessions, a drought-tolerant genotype was selected to be used as a rootstock. It was tested in productivity terms (A25 code) and showed an increase in marketable fruit of $118 \%$ versus nongrafted plants (Penella et al., 2017).

Thus present work aimed to (i) determine if shortterm drought stress exposure of seedling grafted plants onto A25 could express its tolerance to determine the highest productivity (Penella et al., 2017); (ii) identify rootstock and scion physiological traits associated with drought tolerance to open up new strategies that improve crop performance under limited water supply conditions. Very few studies on simultaneous changes in the rootstock/scion are available, but none about the perception of scions and rootstock remodeling can be found (Li et al., 2014; Liu et al., 2016). To fulfill these objectives, we compared the behavior of photosynthetic, water relations, antioxidant mechanisms and oxidative index stress in non-grafted and self-grafted plants, and in those grafted onto a tolerant rootstock (A25), under drought stress and control conditions.

\section{MATERIALS AND METHODS}

\section{Experimental Site and Greenhouse Conditions}

The experiment was conducted in a Venlo-type glasshouse located in Moncada (Valencia, Spain; Latitude: 39.58951793357715, Longitude: $-0.3955507278442383,37 \mathrm{~m}$ above sea level) at the IVIA research institute.

During the experiments, plants were grown under natural light conditions with a maximum PAR of $1000 \mu \mathrm{mol} \mathrm{m}^{-2} \mathrm{~s}^{-1}$ $\left(800-1,000 \mu \mathrm{mol} \mathrm{m}{ }^{-2} \mathrm{~s}^{-1}\right)$, a mean temperature of $22^{\circ} \mathrm{C}(18-$ $25^{\circ} \mathrm{C}$ ) and a mean humidity of $60 \%(50-70 \%)$.

\section{Plant Material and Management}

Based on previous studies, a pepper accession of Capsicum annuum $\mathrm{L}$. was used as a tolerant rootstock to water scarcity (code A25). Pepper cultivar "Adige" (code A) (Lamuyo type, Sakata Seeds, Japan) was used as a scion. Seeds were sown in March 2016 in 54-hole seed trays filled with enriched substrate for germination. Three months after sowing, plants were grafted by the tube-grafting method (Penella et al., 2014b).

Three weeks after grafting (June 2016), seedlings were removed from substrate, and their roots were cleaned before being placed in $5 \mathrm{~L}$ polyethylene pots covered with aluminum 
sheets. Pots were filled with a nutrient solution containing (in mmol L${ }^{-1}$ ): $12.3 \mathrm{NO}_{3}{ }^{-}, 1.02 \mathrm{H}_{2} \mathrm{PO}_{4}, 2.45 \mathrm{SO}_{4}{ }^{2-}, 3.24$ $\mathrm{Cl}^{-}, 0.6 \mathrm{NH}_{4}^{+}, 5.05 \mathrm{~K}^{+}, 4.23 \mathrm{Ca}^{2+}, 2.55 \mathrm{Mg}^{2+}, 2.2 \mathrm{Na}^{+}$and micronutrients $\left(15.8 \mu \mathrm{M} \mathrm{Fe}^{2+}, 10.3 \mu \mathrm{M} \mathrm{Mn}^{2+}, 4.2 \mu \mathrm{M} \mathrm{Zn}^{2+}\right.$, $43.5 \mu \mathrm{M} \mathrm{B}^{+}, 2.14 \mu \mathrm{M} \mathrm{Cu}^{2+}$ ), which were artificially aerated with an air pump. Electrical conductivity and $\mathrm{pH}$ were $2.14 \mathrm{dS}$ $\mathrm{m}^{-1}$ and 6.7, respectively. Nutrient solution was added daily to compensate absorption. The water stress treatment was induced after a 7-day seedling acclimation in pots by adding 5\% PEG 8000 (Sigma Co.) to the nutrient solution. The osmotic potential of the solutions, measured by a vapor osmometer (Digital osmometer, Wescor, Logan, UT, United States), was $-0.55 \mathrm{MPa}$ for 5\% PEG and $-0.05 \mathrm{MPa}$ for the control solution (0\% PEG).

The assay was based on three plant combinations: A (nongrafted plants of cultivar Adige), A/A (A grafted onto itself by showing the graft effect) and A/A25 (A grafted onto the A25 rootstock). The layout was completely randomized with four replications for each combination and six plants per replication.

All the physiological measurements were taken 1, 2, 4, and 7 days after treatment began (DAT). Measurements were taken in fully and expanded mature leaves (third to fourth leaf from the shoot apex), and also in lateral roots for some physiological measurements. The layout was randomized with 12 measurements (three plants per replication) per plant combination and treatment for the gas exchange measurement, and with four measurements (one plant per replication) in the other analysis of the physiological parameters. Biomass determinations were made only on 7 DAT using the plants that were not involved in the physiological measurements. Eight plants per plant combination and treatment were analyzed (two plants per replication).

\section{Gas Exchange Measurements}

The $\mathrm{CO}_{2}$ assimilation rate $\left(A_{\mathrm{N}}, \mu \mathrm{mol} \mathrm{CO} \mathrm{m}^{-2} \mathrm{~s}^{-1}\right)$, stomatal conductance to water vapor $\left(g_{\mathrm{s}}, \mathrm{mol} \mathrm{H}_{2} \mathrm{O} \mathrm{m}^{-2} \mathrm{~s}^{-1}\right)$, and substomatal $\mathrm{CO}_{2}$ concentration $\left(C_{\mathrm{i}}, \mu \mathrm{mol} \mathrm{CO} \mathrm{mol}^{-1}\right.$ air $)$ were measured with a portable LI-COR 6400 infrared gas analyzer (Li-Cor Inc., United States). Measurements were taken under saturating light conditions $\left(1,000 \mu \mathrm{mol}\right.$ quanta $\left.\mathrm{m}^{-2} \mathrm{~s}^{-1}\right)$, with reference $\mathrm{CO}_{2}\left(400 \mu \mathrm{mol} \mathrm{CO} \mathrm{mol}^{-1}\right)$ at $24^{\circ} \mathrm{C}\left(24^{\circ} \mathrm{C} \pm 2\right)$ and $75 \%$ relative humidity $(75 \% \pm 10)$. The fully expanded (third to fourth leaf from the apex) and non-detached leaves were used for the measurements taken from 09:00 h to 11:00 h (UT + 01:00 h).

\section{Biomass Determination}

Root length and the fresh weight of roots and leaves were measured at the end of the experiment (7 DAT). Fresh roots and leaves were dried at $65^{\circ} \mathrm{C}$ for $72 \mathrm{~h}$ to determine dry weight.

\section{Water Relations}

Relative water content (RWC) was measured by weighing leaves before and after a $24 \mathrm{~h}$ rehydration with distilled water. Next they were dried at $65^{\circ} \mathrm{C}$ for $72 \mathrm{~h}$ and the measurement was repeated. RWC was determined by the equation $\mathrm{RWC}=(\mathrm{FW}-\mathrm{DW}) /(\mathrm{TW}-\mathrm{DW}) \times 100$, where $\mathrm{FW}$, DW, and TW are fresh weight, dry weight, and turgid weight, respectively.
The leaf water potential at pre-dawn $\left(\Psi_{\mathrm{w}}\right)$ was measured with a Schlolander pressure chamber (Wescor Model 600, PMS Instruments, Albany, NY, United States) on detached fresh and mature leaves inside a greenhouse.

The osmotic potential of leaf sap $\left(\Psi_{\mathrm{s}}\right.$ in $\left.\mathrm{MPa}\right)$ was measured by an osmometer (Digital osmometer, Wescor, Logan, UT, United States). Leaves were detached, placed inside $1 \mathrm{~mL}$ tubes and quickly frozen at $-20^{\circ} \mathrm{C}$. After melting, sap was collected by centrifugation at $9,000 \mathrm{rpm}$ for $1 \mathrm{~min}$ in $1.5 \mathrm{~mL}$ tubes to be used for the osmometer measurements. Osmolyte content ( $\mathrm{mmol}$ $\mathrm{kg}^{-1}$ ) was converted into MPa by the Van't Hoff equation.

\section{Nitrate Reductase Activity}

Nitrate reductase activity (Enzyme Code 1.7.1.1) was determined in vivo following the methods described by Hageman and Hucklesby (1971) and Jaworski (1971). Disks of $1 \mathrm{~cm}$ diameter from mature fresh leaves or $1 \mathrm{~cm}$ root pieces were collected. Samples $(0.2 \mathrm{~g})$ were suspended in plastic vials containing $10 \mathrm{~mL}$ of $100 \mathrm{mM}$ potassium phosphate buffer ( $\mathrm{pH} 7.5), 1 \%(\mathrm{v} / \mathrm{v})$ n-propanol and $100 \mathrm{mM} \mathrm{KNO}_{3}$. Plant samples were incubated in a water bath at $30^{\circ} \mathrm{C}$ for $60 \mathrm{~min}$ in the dark and placed in a boiling water bath for $5 \mathrm{~min}$ to stop the enzymatic reaction. The nitrite released from plant material was determined colorimetrically at $540 \mathrm{~nm}$ (spectrophotometer PerkinElmer, Lambda 25) by adding $0.02 \%$ (w/v) $N$-naphthyl-ethylenediamine and $1 \%(\mathrm{w} / \mathrm{v})$ sulfanilamide. A standard curve with $\mathrm{KNO}_{2}$ was prepared to calculate the amount of $\mathrm{NO}_{2}$ contained in the samples.

\section{Determination of DPPH Radical-Scavenging Capacity}

Determination of radical scavenging capacity (RSA) was carried out by the 2,2-diphenyl-1-picrylhydrazyl (DPPH) radical scavenging method, proposed by Brand-Williams et al. (1995) with modifications. First $0.1 \mathrm{~g}$ of sample (leaves and roots) was frozen in liquid nitrogen and stored at $-80^{\circ} \mathrm{C}$. Samples were ground by a mortar with the addition of $80 \%(\mathrm{v} / \mathrm{v})$ methanol. After $12 \mathrm{~h}$ at $4^{\circ} \mathrm{C}$ in a mixer, samples were centrifuged for $10 \mathrm{~min}$ at $10,000 \times g$ and $4^{\circ} \mathrm{C}$. A $10 \mu \mathrm{L}$ volume of sample and $990 \mu \mathrm{L}$ of $0.065 \mathrm{mM} \mathrm{DPPH}$ were taken and incubated for $30 \mathrm{~min}$ in the darkness at room temperature. Absorbance was measured at $515 \mathrm{~nm}$. The percentage of inhibition of the DPPH radical was measured by the equation: [(DPPH absorption - sample absorption)/DPPH absorption] $\times 100$.

\section{Total Phenolic Content Analysis}

Total phenolic content was determined according to Koç et al. (2010) with modifications. The fresh leaf and root samples $(0.1 \mathrm{~g})$ were frozen in liquid nitrogen and stored at $-80^{\circ} \mathrm{C}$. They were mixed with $1.5 \mathrm{~mL}$ of extraction solution [50\% (v/v) methanol and $1 \%(\mathrm{v} / \mathrm{v}) \mathrm{HCl}]$. Samples were extracted in a boiling bath at $80^{\circ} \mathrm{C}$ for $15 \mathrm{~min}$. Then $0.1 \mathrm{~mL}$ of root extract and $0.02 \mathrm{~mL}$ of leaf extract (diluted in $0.08 \mathrm{~mL}$ extraction solution) were mixed with $0.7 \mathrm{~mL}$ of Folin-Ciocalteu solution (Sigma-Aldrich ${ }^{\circledR}$ ), diluted in the 1:10 proportion, and with $0.7 \mathrm{~mL}$ of $6 \%(\mathrm{w} / \mathrm{v}) \mathrm{Na}_{2} \mathrm{CO}_{3}$. Samples were incubated at room temperature and in the darkness 
for $1 \mathrm{~h}$ before being subjected to absorbance measurement at $765 \mathrm{~nm}$. Gallic acid was used as a standard.

\section{Determination of Hydrogen Peroxide}

$\mathrm{H}_{2} \mathrm{O}_{2}$ content was determined according to Sergiev et al. (1997) and Velikova et al. (2000) with slight modifications. First $0.25 \mathrm{~g}$ of FW (leaves and roots) was frozen in liquid nitrogen and conserved at $-80^{\circ} \mathrm{C}$. Samples were ground with a mortar and $2 \mathrm{~mL}$ of $0.1 \%(\mathrm{w} / \mathrm{v})$ trichloroacetic acid (TCA). The homogenate was centrifuged at $10,000 \times g$ at $4^{\circ} \mathrm{C}$ for $8 \mathrm{~min}$. With the root samples, $1 \mathrm{~mL}$ of the supernatant was added to $0.5 \mathrm{~mL}$ of $100 \mathrm{mM}$ potassium phosphate buffer $(\mathrm{pH}=7)$ and $2 \mathrm{~mL}$ of $1 \mathrm{M} \mathrm{KI}$. For another set of samples, $0.4 \mathrm{~mL}$ of leaves was diluted with $0.6 \mathrm{~mL}$ of $0.1 \%(\mathrm{w} / \mathrm{v})$ TCA. Samples were incubated for $1 \mathrm{~h}$ at room temperature under dark conditions. Absorbance was measured at $390 \mathrm{~nm} . \mathrm{H}_{2} \mathrm{O}_{2}$ content was given by a $\mathrm{H}_{2} \mathrm{O}_{2}$ standard curve.

\section{Lipid Peroxidation Analysis}

Lipid peroxidation was estimated through malondialdehyde (MDA) determinations by the thiobarbituric acid reaction, according to the protocol reported by Heath and Packer (1968), and modified in Dhindsa et al. (1981). First $0.1 \mathrm{~g}$ of sample (leaves and roots) was frozen in liquid nitrogen and kept at $-80^{\circ} \mathrm{C}$. Samples were ground with a mortar and $2 \mathrm{~mL}$ of $0.1 \%$ $(w / v)$ TCA. Later the homogenate was centrifuged at $10,000 \times g$ and $4^{\circ} \mathrm{C}$ for $5 \mathrm{~min}$. Afterward, $2 \mathrm{~mL}$ of reaction buffer (TCA $20 \%+$ TBA $0.5 \%$ ) were added and heated at $95^{\circ} \mathrm{C}$ for $30 \mathrm{~min}$. The non-specific background absorbance reading at $600 \mathrm{~nm}$ was subtracted from the specific absorbance reading at $532 \mathrm{~nm}$.

\section{Statistical Analysis}

The experiment was completely randomized, and every time measurements were separately subjected to a two-way ANOVA (Statgraphics Centurion for Windows, Statistical Graphics Corp.), where plant combinations and treatments were the factors of the analyses. After verifying the significance of the interaction for each variable (data not shown), a one-way ANOVA was performed by joining the plant combination and treatment. Means were compared by the Fisher's least significance difference (LSD) test at $P<0.05$. There were no significant differences among replicates for each measured parameter.

\section{RESULTS}

\section{Gas Exchange Measurements}

At $24 \mathrm{~h}$ after PEG addition, $A_{\mathrm{N}}$ dramatically dropped in the A plants, followed by the A/A plants compared to their control (Figure 1A), while plants A/A25 showed no significant differences between PEG treatment and the control. At the end of the experiment (7 DAT), all the plant combinations displayed significant differences with their control. The highest values went to the A/A25 control, followed by A/A25 PEG. The $g_{\text {s }}$ values (Figure 1B) changed significantly from the beginning of the experiment in all the plant combinations, when low $g_{s}$ values were recorded for plants $\mathrm{A}$ and $\mathrm{A} / \mathrm{A}$ under PEG. Parameter $C_{\mathrm{i}}$ was higher in plants $\mathrm{A}$ and $\mathrm{A} / \mathrm{A}$ under the PEG conditions on 4 DAT

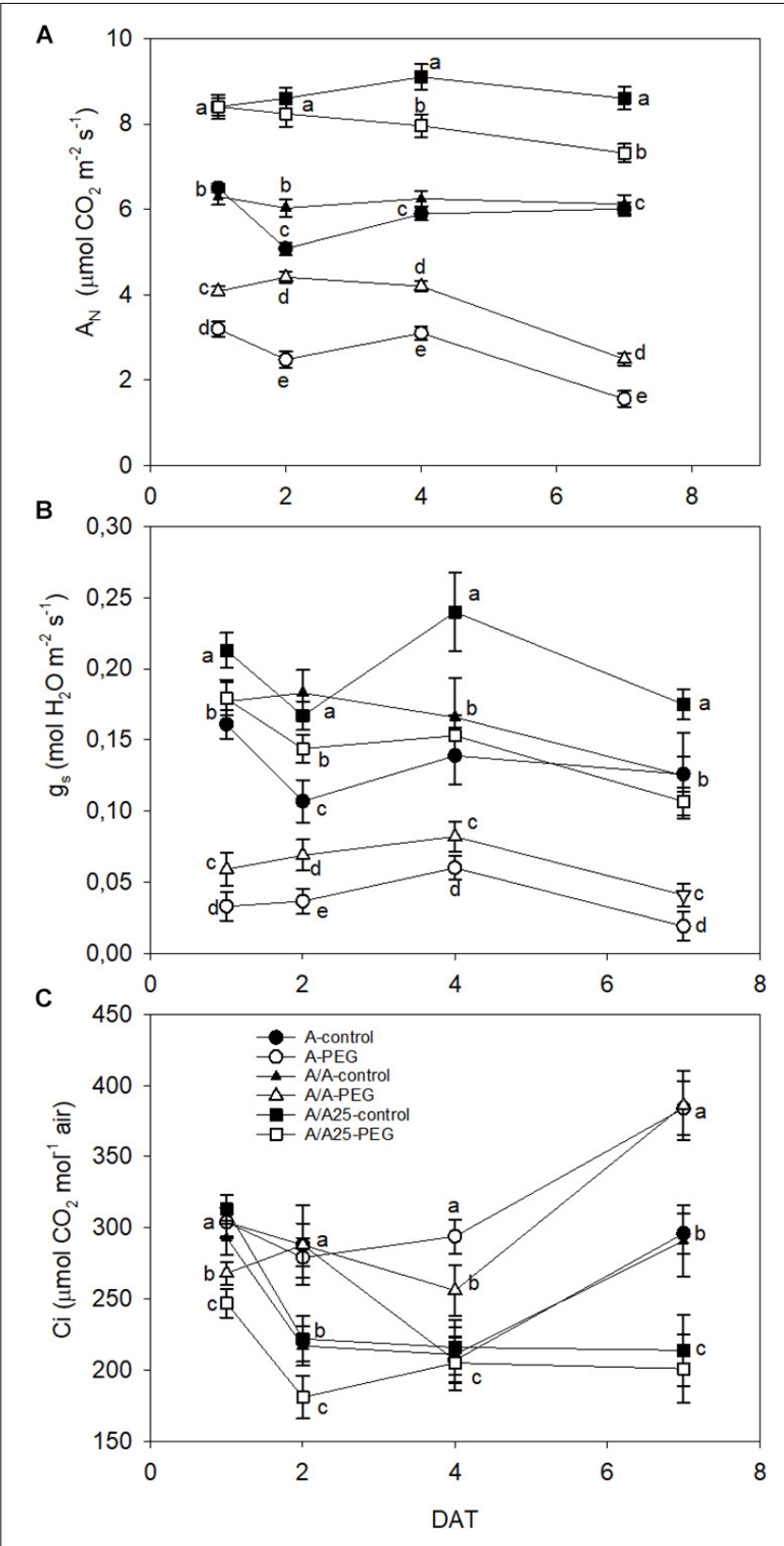

FIGURE 1 | $\mathrm{Net} \mathrm{CO}_{2}$ assimilation rate $\left(A_{\mathrm{N}} ; \mu \mathrm{mol} \mathrm{CO}_{2} \mathrm{~m}^{-2} \mathrm{~s}^{-1}\right)$ (A); leaf stomatal conductance $\left(g_{\mathrm{s}} ; \mathrm{mol} \mathrm{H}_{2} \mathrm{O} \mathrm{m}^{-2} \mathrm{~s}^{-1}\right)$ (B) and substomatal $\mathrm{CO}_{2}$ concentration $\left(C_{i} ; \mu \mathrm{mol} \mathrm{CO} \mathrm{Col}^{-1}\right.$ air) (C) in the non-grafted pepper plants (cultivar Adige, A), self-grated plants (A/A), and plants grafted onto A25 (AVA25) at 0\% PEG (control) or 5\% PEG (water stress). Measurements were taken on 1 DAT, 2 DAT, 4 DAT, and 7 DAT (days after treatment with PEG began). Data are the mean values for $n=12 \pm$ SE. For each studied time, different letters indicate significant differences at $P<0.05$ (LSD test).

and 7 DAT (Figure 1C), but showed no significant differences for plants A/A25.

\section{Biomass Parameters}

At the end of the experiment (7 DAT), root length (Figure 2A), root DW (Figure 2B), and leaf DW (Figure 2C) decreased, 

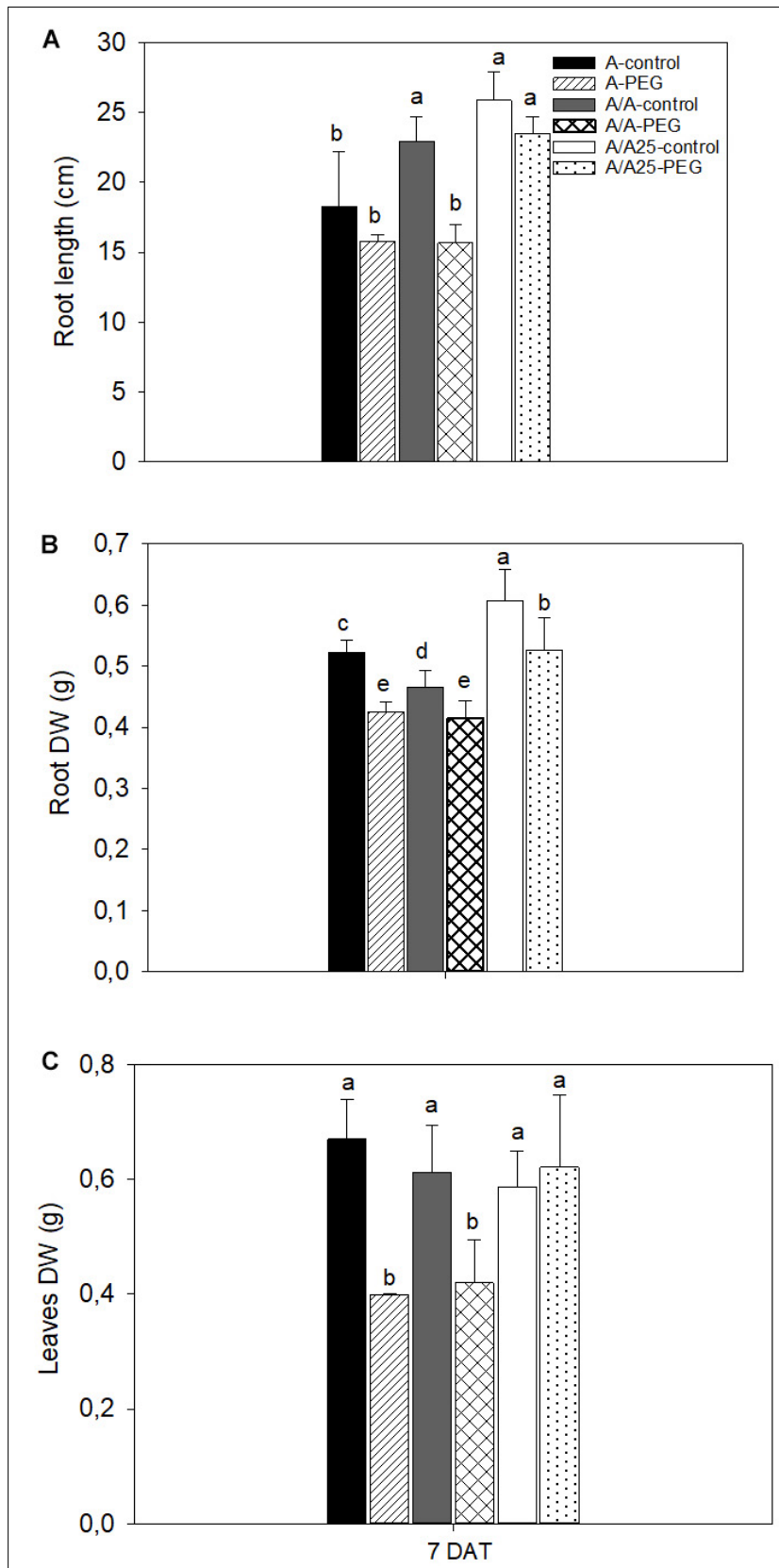

FIGURE 2 | Root length (A), root dry weight (DW) (B), and leaf dry weight (C) in the non-grafted pepper plants (cultivar Adige, A), self-grated plants (A/A), and plants grafted onto A25 (A/A25) at 0\% PEG (control) or 5\% PEG (water stress). Measurements were taken at the end of the experiment, 7 days after treatment with PEG began (7 DAT). Data are the mean values for $n=8 \pm$ SE. For each studied time, different letters indicate significant differences at $P<0.05$ (LSD test).

with significant differences in the $\mathrm{A}$ and $\mathrm{A} / \mathrm{A}$ plants exposed to stress compared with their control treatments. The A/A25 plants exposed to PEG underwent changes in root DW, with a significant decrease compared to the control plants, which was not the case for the other biomass parameters (root length and leaf DW). Under the control conditions, the biomass parameters

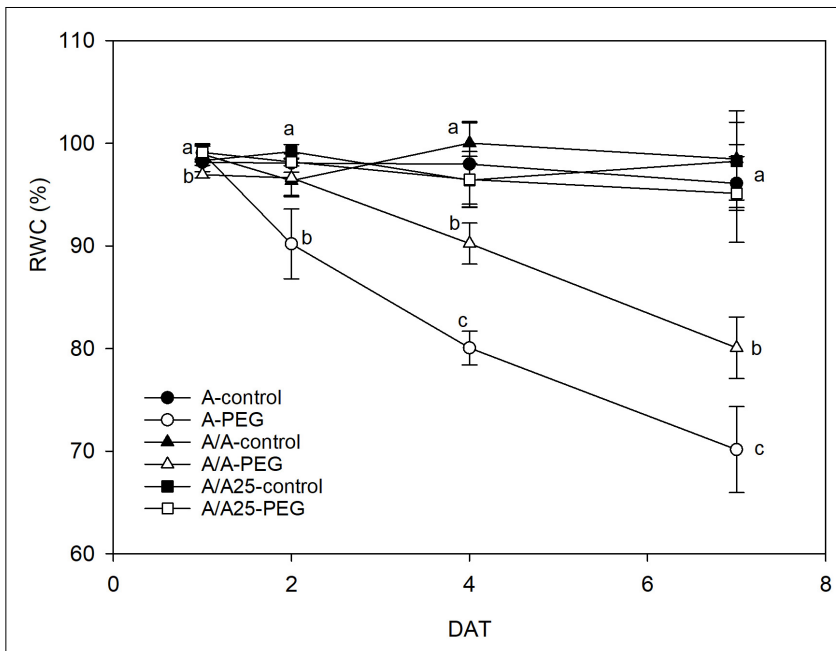

FIGURE 3 | Effect of PEG addition at 0\% (control) and 5\% (water stress) on relative water content (RWC) on 1 DAT, 2 DAT, 4 DAT, and 7 DAT (days after treatment with $P E G$ began) in the non-grafted pepper plants (cultivar Adige, A), self-grated plants (A/A), and plants grafted onto A25 (A/A25). Data are the mean values for $n=4 \pm$ SE. For each studied time, different letters indicate significant differences at $P<0.05$ (LSD test).

were higher in the A/A25 plants for the root traits compared with plants $\mathrm{A}$ and $\mathrm{A} / \mathrm{A}$.

\section{Hydric and Osmotic Relations}

During the experiment, the pepper plants under the control conditions maintained a constant leaf RWC (Figure 3) above a value of $95 \%$. The presence of PEG in the nutrient solution provoked a reduction in RWC from 2 DAT, which became more evident on 7 DAT for the A plants, followed by the A/A plants. The RWC in the A/A25 plants exposed to drought stress remained stable with similar values in the control plants during the experiment.

The leaf water potential $\left(\Psi_{\mathrm{W}}\right)$ in the control plants did not show any significant difference for each measured time (Figure 4). The A plants under PEG showed changes in $\Psi_{\mathrm{W}}$ after $24 \mathrm{~h}$ after exposure to stress (1 DAT), which remained stable on 2 DAT and 4 DAT, when both had similar values. Then a sharp drop was observed on 7 DAT. In the A/A plants under the stress conditions, the drop in $\Psi_{\mathrm{W}}$ started on 2 DAT and reached a maximum decrease on 7 DAT. For the A/A25 plants under PEG, the $\Psi_{\mathrm{W}}$ values during the experiment were similar to the control plants.

The $\Psi_{S}$ (Figure 5) lowered in relation to the exposure time to PEG. Within the first measured time frame (1 DAT), plants $\mathrm{A}$ and A/A displayed a drop in $\Psi_{\mathrm{S}}$ under the stress conditions, which was not found for plants A/A25. On 7 DAT, the maximal decrease was found for A, followed by plants A/A and A/A25.

\section{Nitrate Reductase Activity}

Nitrate reductase activity (NR) was higher in leaves (Figure 6A) than in roots (Figure 6B). In general terms, the opposite behavior was observed between both organs in activity terms during the 


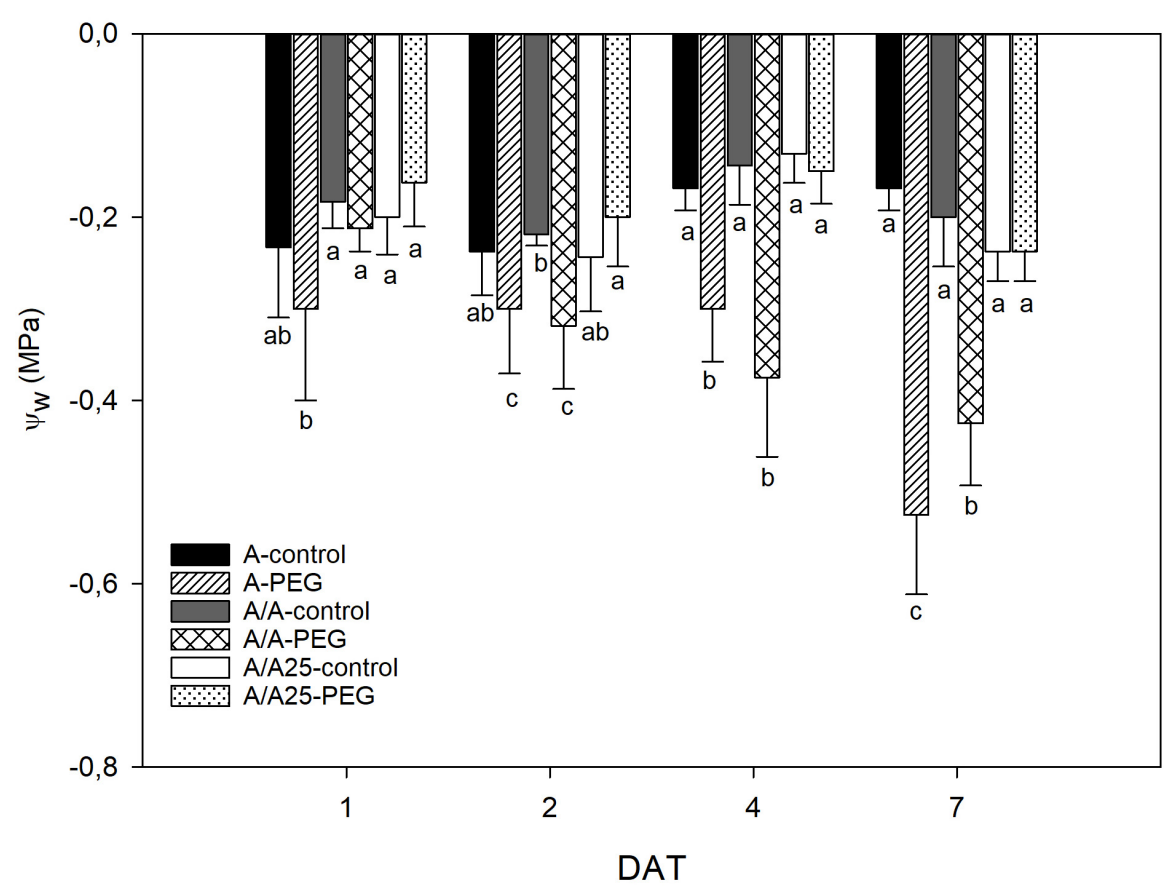

FIGURE 4 | Leaf water potential (MPa) in the non-grafted pepper plants (cultivar Adige, A), self-grated plants (A/A), and plants grafted onto A25 (A/A25) after addition of $0 \%$ PEG addition (control) and 5\% PEG on 1 DAT, 2 DAT, 4 DAT, and 7 DAT (days after treatment with PEG began). Data are the mean values for $n=4 \pm$ SE. For each studied time, different letters indicate significant differences at $P<0.05$ (LSD test).

experiment, with higher values in leaves that matched the lower values in roots for each time and plant combination. In leaves (Figure 6A), NR dramatically lowered $24 \mathrm{~h}$ after adding PEG to the A plants, but this decrease in the A/A plants was less marked compared with the A plants. On 2 DAT, the A/A plants underwent a sharp drop in NR activity under water stress, and the A/A25 plants underwent a reduction only on 7 DAT. In roots (Figure 6B), NR activity increased in all the pepper plant combinations under drought stress compared with the control plants from 1 DAT to 2 DAT. Afterward, activity lowered until 7 DAT, when the lowest values were obtained in the A/A25 plants, followed by A/A and finally A.

\section{DPPH-Radical Scavenging Activity}

The leaves of the plants grown under drought stress displayed an increasing percentage of inhibition of the DPPH radical (Figure 7A). For the A plants under PEG, the increase was recorded earlier (1 DAT), whereas DPPH-RSA started from 4 DAT in A/A and A/A25. For the plants under drought stress on 7 DAT, maximum activity was found for the A plants followed by A/A, with minor activity for A/A25. DPPH-RSA was higher in leaves than in roots (Figure 7 ). In roots, major activity was exhibited on 1 DAT and 2 DAT in the plants exposed to PEG (Figure 7B). Afterward no significant differences were found in activity among treatments.

\section{Total Phenolic Content}

An increase in phenolic content was observed during the experiment in the leaves of the plants exposed to drought stress
(Figure 8A). The most marked phenolic increase was found for plants A in the PEG treatment, with significant differences shown on 4 DAT and 7 DAT compared to the control plants. In roots (Figure 8B), phenolic contents were 10-fold lower than in leaves, and values were similar among treatments, except for the A/A plants under drought stress at 2 DAT, when a sharp drop was observed.

\section{$\mathrm{H}_{2} \mathrm{O}_{2}$ Concentration}

The hydrogen peroxide level in leaves (Figure 9A) increased after exposing plants to drought stress from 4 DAT to 7 DAT, which was emphasized mainly in plants A and A/A with significant differences compared to the control plants. In roots (Figure 9B), the $\mathrm{H}_{2} \mathrm{O}_{2}$ concentration was approximately 10 -fold lower than in leaves. The maximum concentrations for all the plant combinations were recorded on 2 DAT. At the end of the experiments, no significant differences were observed between plants and treatments.

\section{Lipid Peroxidation}

The MDA concentration in leaves increased with time from 2 DAT (Figure 10A). As a result, the highest MDA levels were found in the A plants, followed by the A/A plants under drought stress, and the A/A25 plants on 7 DAT. In roots (Figure 10B), lipid peroxidation increased and followed this trend in leaves during the experiment. On 7 DAT, the highest values were recorded for pepper plants $\mathrm{A}$ and $\mathrm{A} / \mathrm{A}$ under drought stress. 


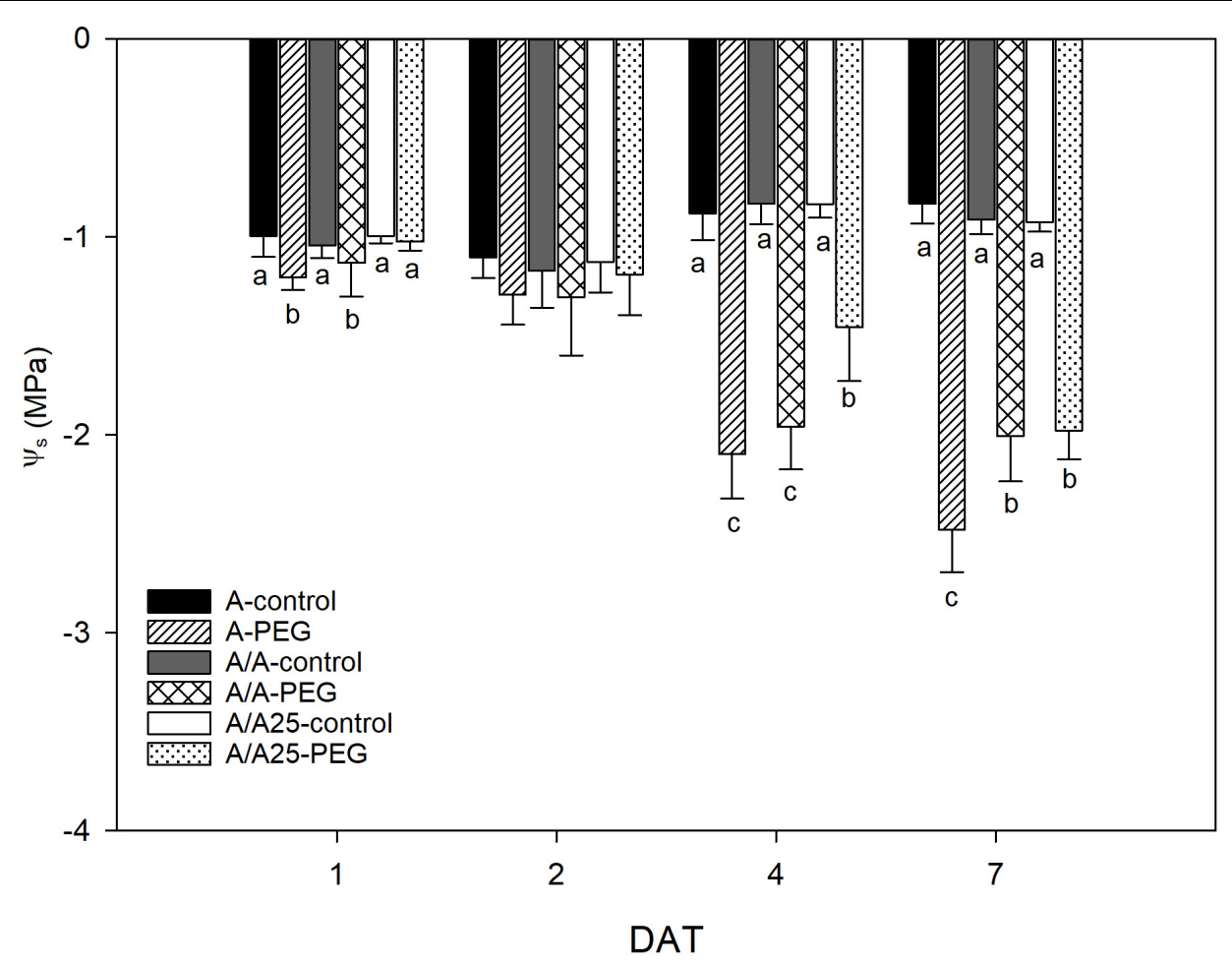

FIGURE 5 | Leaf osmotic potential (MPa) in the non-grafted pepper plants (cultivar Adige, A), self-grated plants (A/A), and plants grafted onto A25 (A/A25) after addition of 0\% PEG (control) and 5\% PEG on 1 DAT, 2 DAT, 4 DAT, and 7 DAT (days after treatment with PEG began). Data are the mean values for $n=4 \pm$ SE. For each studied time, different letters indicate significant differences at $P<0.05$ (LSD test). The absence of letters on 2 DAT means no significant difference for both factors (plant and treatment).

\section{DISCUSSION}

In this experiment, we observed numerous changes in the biochemical and physiological processes during the short drought stress treatment, which were provoked by the addition of $5 \%$ PEG. These processes were involved in the perception and transduction of stress in the scion depending on the employed rootstock. We found that pepper plants with the A25 rootstock (A/A25) displayed greater tolerance to drought stress in this short-term experiment, as indicated by the effects on the scion in terms of biomass conservation, photosynthesis and RWC maintenance, lower lipid peroxidation and greater NR activity in leaves compared with the non-grafted and self-grafted pepper plants. The fact that the scion (A) suffered less drought stress was related to the better tolerance of root parts (A25), which encompassed the greater vigor root system and the lower $\mathrm{H}_{2} \mathrm{O}_{2}$ concentration, lipid peroxidation and NR activity. These results indicated that scion performance is largely dependent on the tolerance of roots to drought stress, although the root to shoot communication involved in scion pepper stress responses is largely unknown.

In whole-plant terms, the effect of abiotic stresses is usually noticed as a reduction in photosynthesis and growth, and is associated with alterations in carbon and nitrogen metabolism (Loggini et al., 1999; García-Mata and Lamattina, 2001). To support this idea, in our experiment drought stress negatively affected the aboveground mass production in the non-grafted and self-grafted pepper plants. The least biomass loss was found in the pepper plants of the Adige variety, grafted onto the A25 rootstock, which have been previously defined as tolerant, while Adige has been described as drought-sensitive (Penella et al., 2017). Different drought stress effects were observed for the growth parameters in both roots and leaves; the growth inhibition of roots (DW) was lower (a reduction of 19\% in A, $11 \%$ in $\mathrm{A} / \mathrm{A}$ and $13 \%$ in $\mathrm{A} / \mathrm{A} 25$ compared to their controls) versus leaves at a low osmotic potential of the solution (a reduction of $40 \%$ in $\mathrm{A}, 31 \%$ in $\mathrm{A} / \mathrm{A}$ and a non-effect in A/A25). This result indicated that leaf growth was more sensitive to drought stress compared to roots, except for A/A25 where the effect of PEG was not detected in leaves. This differential response in the growth inhibition between roots and leaves under drought stress (in our results for plants A and A/A) has been observed by several authors (Westgate and Boyer, 1985; Sharp et al., 1994; Hsiao and Xu, 2000). It resulted in a sudden reduction of $\Psi_{\mathrm{W}}$ in roots, which allowed water to enter. Then solutes had to enter to prevent dilution and maintain the osmotic forces needed for growth. On the contrary in leaves, osmotic adjustment occurs by slowly limiting their expansion (Hsiao and Xu, 2000). Beyond the biophysical aspect, there is compelling evidence that ABA accumulation under drought stress plays a pivotal role by inhibiting shoot growth, as in plants $\mathrm{A}$ and A/A, while a minor effect is observed in roots (Sharp et al., 1994). Nevertheless, the 


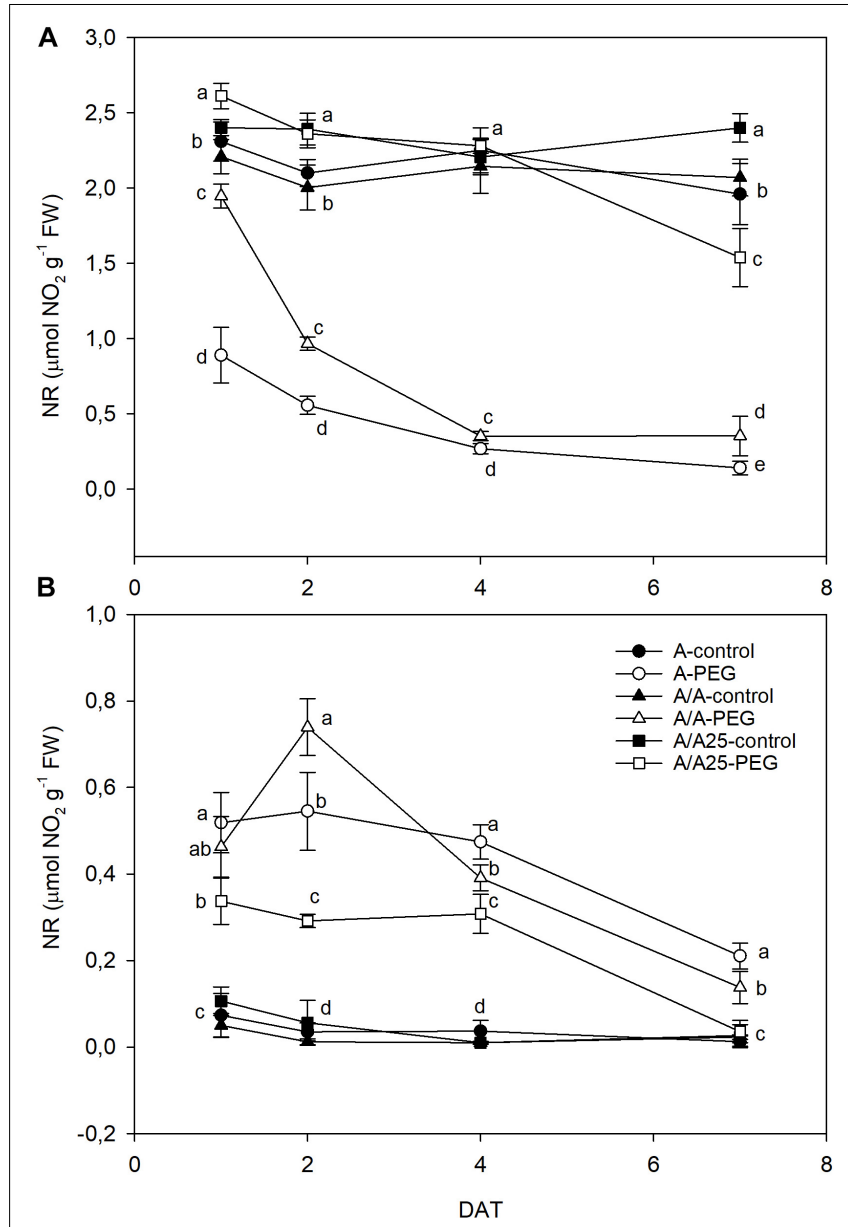

FIGURE 6 | Nitrate reductase activity (NR) in the leaves (A) and roots (B) of the non-grafted pepper plants (cultivar Adige, A), self-grated plants (A/A), and plants grafted onto A25 (A/A25) under the control conditions (0\% PEG) and at $5 \%$ PEG on 1 DAT, 2 DAT, 4 DAT, and 7 DAT (days after treatment with PEG began). Dates are the mean values for $n=4 \pm$ SE. For each studied time, different letters indicate significant differences at $P<0.05$ (LSD test). behavior of plants A/A25 did not match these results. Currently, we have no plausible explanation for this. All these results suggest that scion growth is largely dependent on rootstock tolerance to drought stress.

The growth reductions mediated by drought stress evidence a series of changes in various biochemical processes, such as photosynthesis (Urban et al., 2017). Net $\mathrm{CO}_{2}$ assimilation decreased suddenly $24 \mathrm{~h}$ after adding PEG to A, followed by plants A/A, while A/A25 maintained similar $A_{\mathrm{N}}$ values to the control up to $48 \mathrm{~h}$ (2 DAT); afterward $A_{\mathrm{N}}$ significantly lowered until the end of the experiment, but values were higher in A/A25 than in $\mathrm{A}$ and $\mathrm{A} / \mathrm{A}$ under PEG, with sustained photosynthetic activity during drought (Rouphael et al., 2008; Penella et al., 2014 b). These results agree with previous findings in which grafting onto a tolerant rootstock improved the photosynthesis performance of plants under drought stress (Schwarz et al., 2010; Penella et al., 2014b). In A/A25, the decrease in $A_{\mathrm{N}}$ on 4 DAT and 7 DAT was accompanied by a significant decrease
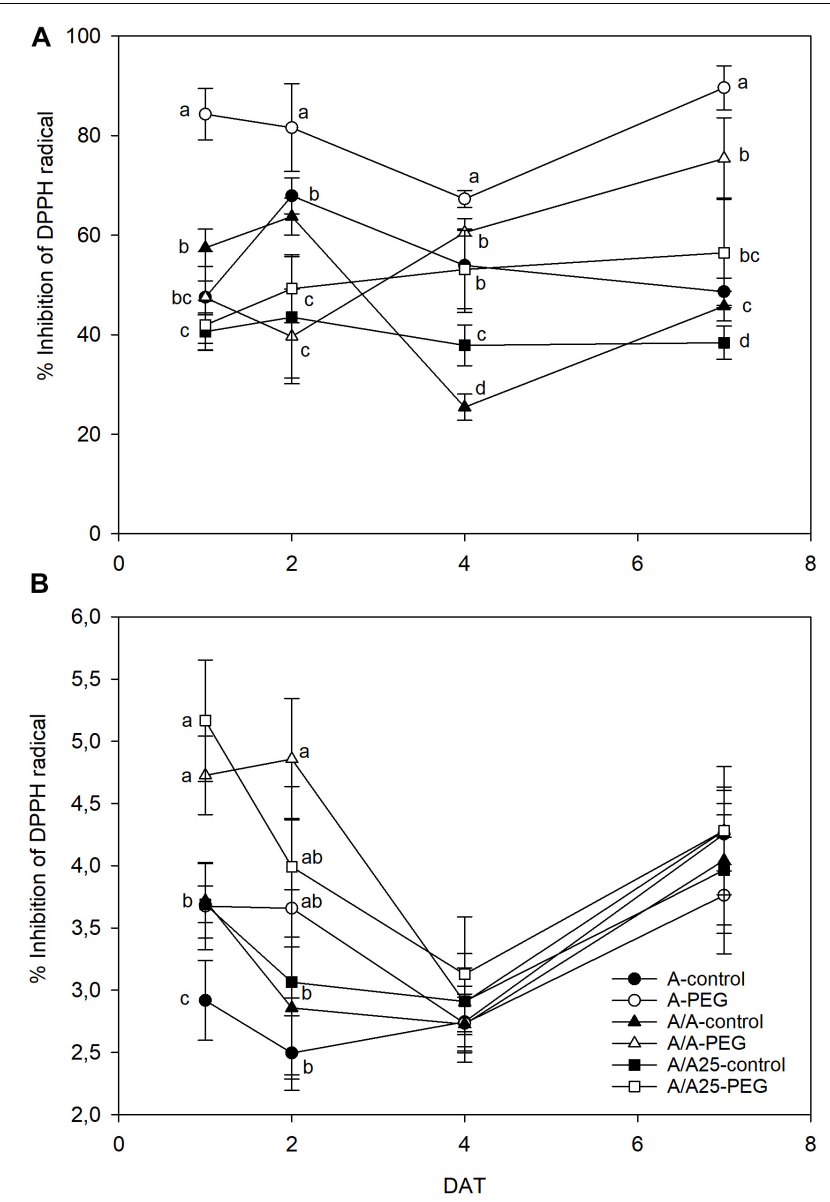

FIGURE 7 | Percentage of inhibition of DPPH radical in the leaves (A) and roots $(\mathbf{B})$ of the non-grafted pepper plants (cultivar Adige, A), self-grated plants (A/A), and plants grafted onto A25 (A/A25) under the control conditions (0\% PEG) and 5\% PEG on 1 DAT, 2 DAT, 4 DAT, and 7 DAT (days after treatment with PEG began). Data are the mean values for $n=4 \pm$ SE. For each studied time, different letters indicate significant differences at $P<0.05$ (LSD test). In (B), the absence of letters on 7 DAT means no significant difference for both factors (plant and treatment).

in stomatal conductance, although the decline in $\mathrm{g}_{\mathrm{s}}$ occurred earlier than the reduction in $\mathrm{CO}_{2}$ fixation (1 DAT and $2 \mathrm{DAT}$ ). We could assume that stomata closure probably did not limit $\mathrm{CO}_{2}$ acquisition by leaves under drought stress within the first two time frames (Delfine et al., 2002). The decrease and the subsequent maintenance of the intercellular $\mathrm{CO}_{2}$ concentration $\left(C_{\mathrm{i}}\right)$ in A/A25 under drought stress (compared to the A/A25 control plants) implied that stomatal limitations were responsible mainly for the reduction in $A_{\mathrm{N}}$ by drought stress (Delfine et al., 2002; Rouphael et al., 2008). In plants A and A/A under drought stress, the drastic decline of $A_{\mathrm{N}}$ was in line with the strong stomata closure from the beginning to the end when time measurements were taken (more marked in the A plants). However, $C_{\mathrm{i}}$ suddenly lowered on 1 DAT, 2 DAT, and 4 DAT, with a significant increase at the end of the experiment compared to the controls, which implies the existence of stomata and non-stomatal limitations related with changes in the cellular 


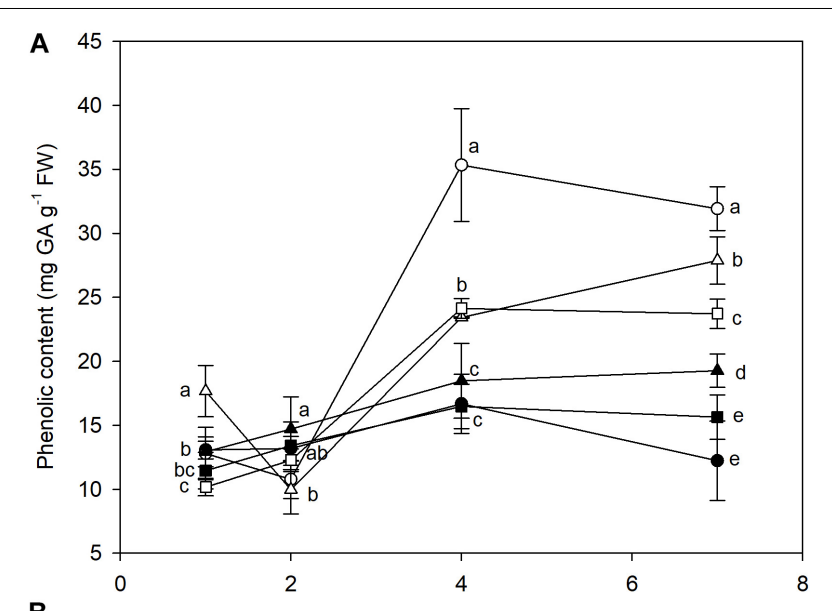

B

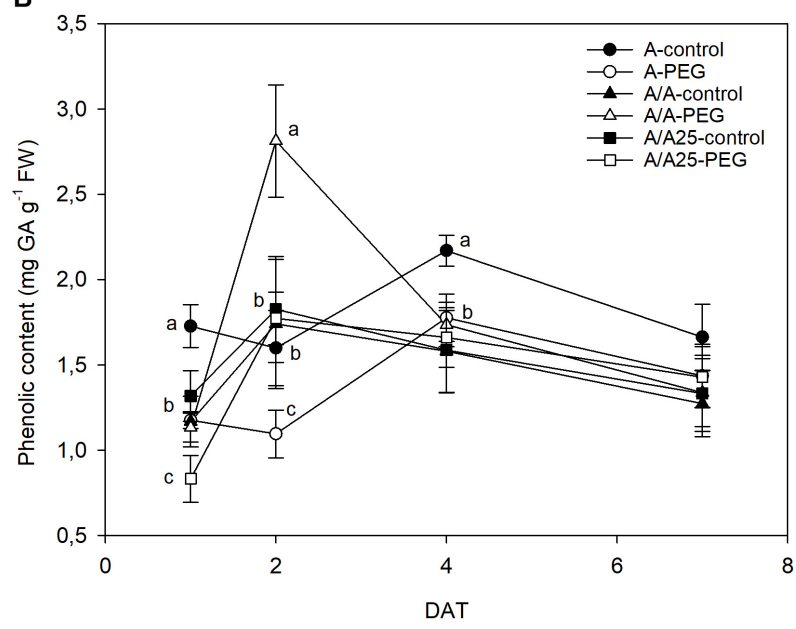

FIGURE 8 | Changes in phenolic content in the leaves (A) and roots (B) of the non-grafted pepper plants (cultivar Adige, A), self-grated plants (A/A), and plants grafted onto A25 (A/A25) under the control conditions (O\% PEG) and 5\% PEG on 1 DAT, 2 DAT, 4 DAT, and 7 DAT (days after treatment with PEG began). Data are the mean values for $n=4 \pm$ SE. For each studied time, different letters indicate significant differences at $P<0.05$ (LSD test). In (B), the absence of letters on 7 DAT means no significant difference for both factors (plant and treatment).

carbon metabolism, which can affect the growth mediated by reducing the biochemical capacity for carbon assimilation and utilization (Flexas et al., 2004; Reddy et al., 2004; He et al., 2009). All this was true, except for plants A/A25, which showed no significant differences between plants under the control and PEG conditions (7 DAT).

Apart from the discussed changes in carbon assimilation, drought stress may affect several nitrogen metabolism stages (Feller and Vaseva, 2014; Penella et al., 2014b) by inducing visible effects on biomass. One important step is the assimilation of nitrate into organic compounds. The activity of the first enzyme involved in this process, NR, was negatively influenced by drought; nitrogen assimilation is also coordinated with carbon assimilation as photosynthesis is required for NR activation (Kaiser and Huber, 2001). Nitrate reduction is sensitive to stomatal resistance and $g_{\mathrm{s}}$ decreases in plants under drought
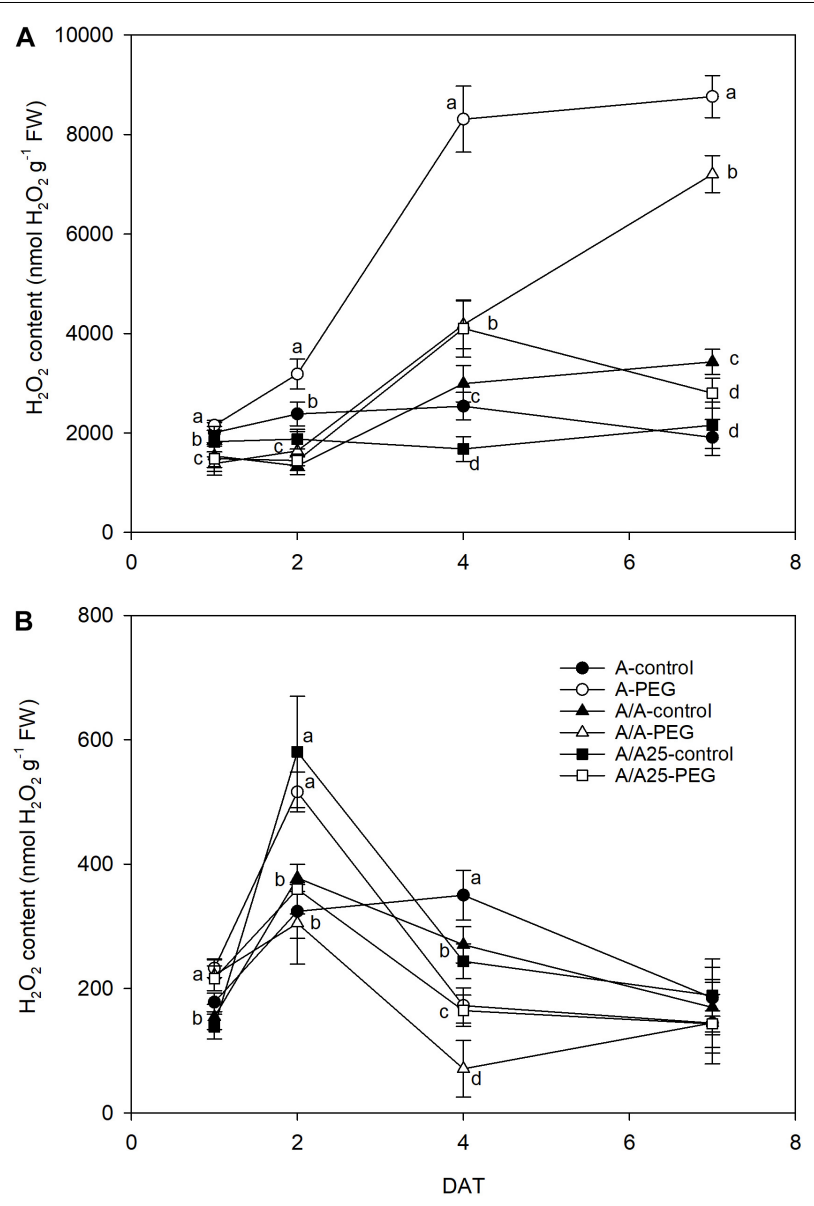

FIGURE 9 | Hydrogen peroxide concentration in the leaves (A) and roots (B) of the non-grafted pepper plants (cultivar Adige, A), self-grated plants $(\mathrm{A} / \mathrm{A})$, and plants grafted onto A25 (A/A25) under the control conditions (0\% PEG) and 5\% PEG on 1 DAT, 2 DAT, 4 DAT, and 7 DAT (days after treatment with PEG began). Data are the mean values for $n=4 \pm$ SE. For each studied time, different letters indicate significant differences at $P<0.05$ (LSD test). In (B), the absence of letters on 7 DAT means no significant difference for both factors (plant and treatment).

stress to preserve water loss when not only $A_{\mathrm{N}}$ drops, but NR also becomes less active (Kaiser and Huber, 2001; Yousfi et al., 2012; Penella et al., 2014b). In relation to this coordination between NR activity and $A_{\mathrm{N}}$, we observed a quick decrease in NR of the A plant leaves $24 \mathrm{~h}$ after inducing drought stress, and after $48 \mathrm{~h}$ in the A/A plants, while the A/A25 plants preserved their activity until 4 DAT. At the end of the experiment, the A plants, followed by A/A, did not show any NR activity and $g_{s}$ dropped, while A/A25 maintained 64\% enzyme activity and sustained $g_{s}$ compared to the control. Some nonstomatal effects, such as reduced nitrate availability in plants, could inhibit NR gene transcription and decrease the stability of NR-mRNAs or post-translational factors, including inactivation through protein phosphorylation, and the induction of proteases could rapidly occur by decreasing NR activity as a result of drought stress (Ferrario et al., 1995; Lillo et al., 2004; Correia et al., 2005). In most herbaceous plants, $\mathrm{NO}_{3}{ }^{-}$assimilation takes place 

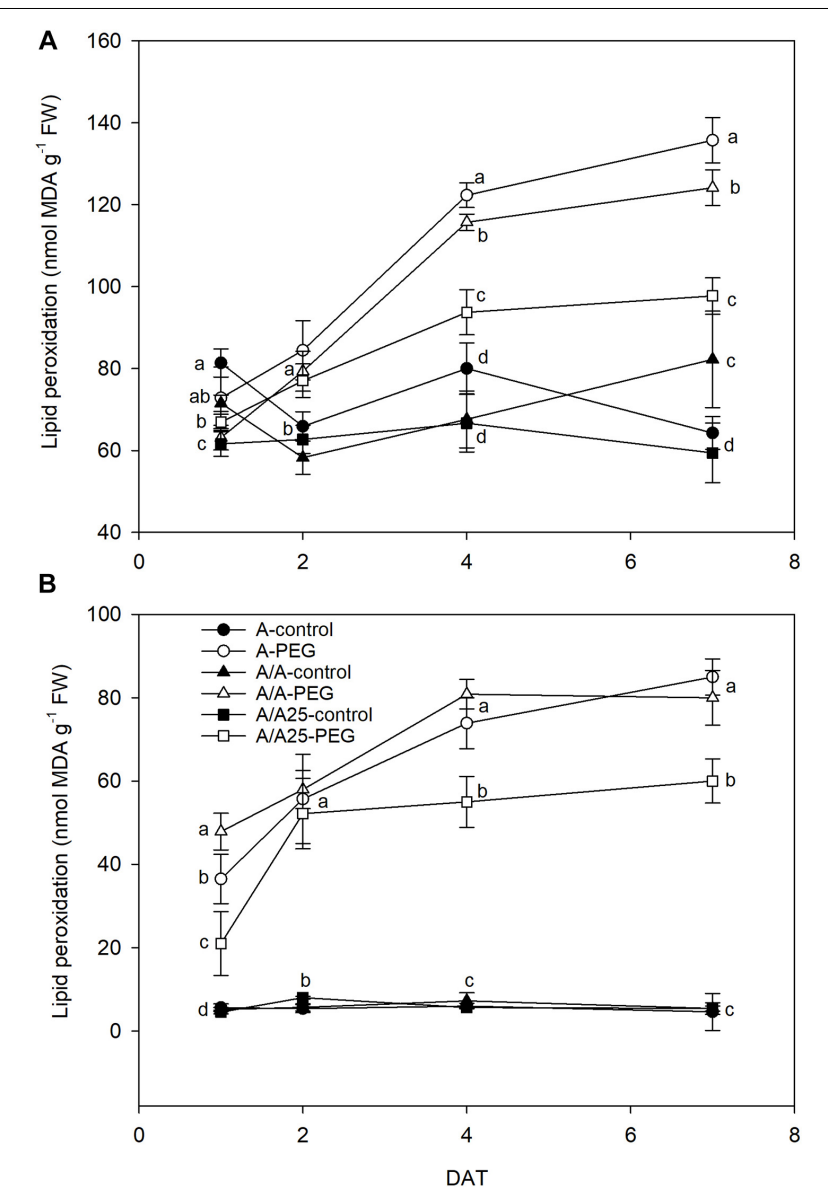

FIGURE 10 | Malondialdehyde content (MDA) of the leaves (A) and roots (B) of the non-grafted pepper plants (cultivar Adige, A), self-grated plants (A/A), and plants grafted onto A25 (A/A25) under the control conditions (0\% PEG) and 5\% PEG on 1 DAT, 2 DAT, 4 DAT, and 7 DAT (days after treatment with PEG began). Data are the mean values for $n=4 \pm$ SE. For each studied time, different letters indicate significant differences at $P<0.05$ (LSD test).

predominantly in leaves (Scheurwater et al., 2002). Accordingly, NR activity was greater in leaves than roots in all the plant combinations and treatments in our study. Nevertheless, the greatest root-NR activity was observed under drought stress, and maximum activities were displayed for the A plants, followed by the A/A plants, where lower leaf NR seemed to be partly compensated by an increase in root NR (Lexa and Cheeseman, 1997; Penella et al., 2014b). Drought stress can decrease nitrate uptake by roots. Besides, the transfer of $\mathrm{NO}_{3}{ }^{-}$to leaves can be limited by stomata closure. Thus transpiration (data not shown) diminished as part of nitrate can reduce in roots. This happened in plants A and A/A as A/A25 had a higher root NR on 1 DAT and 2 DAT, be it to a lesser extent, because the higher $\mathrm{g}_{\mathrm{s}}$ allowed $\mathrm{NO}_{3}{ }^{-}$ transport to leaves for its reduction. This role of NR in leaves and roots under drought stress has been observed in grafted pepper (Penella et al., 2014b), pea (Lexa and Cheeseman, 1997) or wheat plants (Yousfi et al., 2012).

The decrease in $\Psi$ s during the PEG treatment could be a consequence of less water content in tissue and/or through the active osmotic adjustment involving the net accumulation of a range of osmotically active molecules in response to a drop in the $\Psi_{\mathrm{w}}$ in their environment. In pepper, short-term exposure with different osmotic potentials of the nutrient solution (Navarro et al., 2003; Martínez-Ballesta et al., 2004; Silva et al., 2008) showed that the decrease in $\Psi \mathrm{w}$ was not compensated by a reduction in $\Psi$ s and, as a result, the osmotic adjustment was negligible. According to our results, the decrease in the leaves of $\Psi_{\mathrm{w}}, \Psi_{\mathrm{s}}$ and stomatal conductance in the PEG treatment showed that water uptake could not balance water loss and decreased RWC, along with there being fewer biochemical functions in $\mathrm{A}$ and $\mathrm{A} / \mathrm{A}$. This could indicate that osmotic adjustment was insignificant. Nevertheless, RWC was maintained in A/A25 with PEG addition, which could indicate an osmotic adjustment at the end of the experiment, when $\Psi_{\mathrm{w}}$ remained constant and $\Psi$ s decreased. Similar results have been obtained by Penella et al. (2014b). A deep root system and higher root biomass have shown as beneficial effects for acquiring water (Koevoets et al., 2016), and could be one of the reasons for the unchanged RWC values in the A/A25 plants noted throughout the experiment. They suggest a typical conservative water strategy (Tardieu and Simonneau, 1998; García-Sánchez et al., 2010; Sade et al., 2012; Penella et al., 2016). This would lead to more drought tolerance and would allow photosynthesis preservation, improved absorption, upward transfer and $\mathrm{NO}_{3}{ }^{-}$accumulation in leaves. Similar results have been shown in the susceptible tomato scion "Josefina" grafted onto drought stress-tolerant “Zarina” rootstocks (Sánchez-Rodríguez et al., 2013). However, the acclimation rate and drought stress duration are key factors that can influence depending on plant varieties and/or age.

This limited water uptake and $\mathrm{CO}_{2}$ uptake in plants $\mathrm{A}$ and A/A under PEG conditions accelerated oxidative damage by producing ROS (Asada, 1999). Hydrogen peroxide is one type of ROS produced as a result of the dismutation of the superoxide radical, and a higher concentration damages both the cell and the whole plant to result in lipid peroxidation and membrane injury (Sairam and Srivastava, 2001). In the non-grafted tomato plants (Rivero et al., 2003b), a major increase in $\mathrm{H}_{2} \mathrm{O}_{2}$ was observed under thermal shock stress compared with the grafted plants. In $\mathrm{A}$, and to a lesser extent in the $\mathrm{A} / \mathrm{A}$ pepper plants, drought stress caused excessive $\mathrm{H}_{2} \mathrm{O}_{2}$ accumulation in leaves, as well as high lipid peroxidation compared with the A/A25 plants and their controls. This result suggests that $\mathrm{H}_{2} \mathrm{O}_{2}$ in leaves is largely dependent on the adaptability of roots to drought stress. This effect has been observed in cucumber plants grafted onto fig leaf gourd (Cucumis ficifolia) or onto luffa (Luffa cylindrical), where a significantly low $\mathrm{H}_{2} \mathrm{O}_{2}$ concentration alleviated membrane lipid peroxidation at high temperature (Li et al., 2014) compared with non-grafted plants. The authors attributed this reduction to increased $\mathrm{CO}_{2}$ assimilation and ROS-scavenging activity. In roots, the maximum $\mathrm{H}_{2} \mathrm{O}_{2}$ concentration was observed on 2 DAT for the A-PEG and A/A25-control plants, but its concentration was 10-fold lower than in leaves. Afterward, levels lowered in this organ, whose concentration in leaves was "amplified." As a result of increasing $\mathrm{H}_{2} \mathrm{O}_{2}$, the MDA concentration was seen to be enhanced in both roots and leaves, with less lipid peroxidation damage in roots. A lower $\mathrm{H}_{2} \mathrm{O}_{2}$ concentration in A/A25 could be 
due to less ROS production or to the more efficient detoxification of this compound (Rivero et al., 2003b). Antioxidant activity was evaluated by the effect of the extracted samples on the $\mathrm{DPPH}$ radical. Under the PEG conditions and at the end of the experiment, plants A/A25 showed the least radical scavenging activity, which indicates that the alleviation of oxidative stress occurred to a lesser extent in the A/A25 plants compared with the greatest activity in the A plants, followed by the A/A plants. In response to drought stress, plants can accumulate a wide range of antioxidants, including phenolic compounds (Keleş and Öncel, 2002). Phenolic compounds exhibit antioxidant activity by inactivating lipid free radicals or preventing the decomposition of hydroperoxides into free radicals (Pokorny, 2001). Our results showed that with PEG addition, the synthesis of phenols increased, but the most marked rise took place in the A plants, followed by A/A and A/A25. Even though the stimulation of antioxidant activity in plants A and A/A occurred simultaneously with higher phenol concentrations under drought conditions, an imbalance between ROS generation and scavenging systems might have occurred as the highest $\mathrm{H}_{2} \mathrm{O}_{2}$ and MDA levels was confirmed.

According to these results, grafting itself (A/A plants) has a slightly positive effect on the physiological parameters measured under drought stress compared with the A plants, probably due to enhanced endogenous hormone production as a result of the grafting per se incision, which may influence the transport of hormones between roots and the scion that, in turn, could alter weak responses (Aloni et al., 2008; Savvas et al., 2011; Orsini et al., 2013).

\section{CONCLUSION}

To conclude, our results suggest that plants A/A25 were more tolerant to drought stress given the response made in several

\section{REFERENCES}

Alan, O., Ozdemir, N., and Günem, Y. (2007). Effect of grafting on watermelon plant growth, yield and quality. J. Agron. 6, 362-365. doi: 10.3923/ja.2007. 362.365

Aloni, B., Karni, L., Deventurero, G., Levin, Z., Cohen, R., Katzir, N., et al. (2008). Possible mechanism for graft incompatibility between melon scion and pumpkin rootstocks. Acta Hortic. 782, 313-324. doi: 10.17660/ActaHortic.2008. 782.39

Anjum, S. A., Farooq, M., Xie, X., Liu, X., and Ijaz, M. F. (2012). Antioxidant defence system and proline accumulation enables hot pepper to perform better under drought. Sci. Hortic. 140, 66-73. doi: 10.1016/j.scienta.2012.03.028

Asada, K. (1999). The water-cycle in chloroplasts: scavenging of active oxygens and dissipation of excess photons. Annu. Rev. Plant Physiol. Plant Mol. Biol. 50, 601-639. doi: 10.1146/annurev.arplant.50.1.601

Ashraf, M., and Foolad, M. R. (2007). Roles of glycine betaine and proline in improving plant abiotic stress resistance. Environ. Exp. Bot. 59, 206-216. doi: 10.1016/j.envexpbot.2005.12.006

Borsani, O., Valpuesta, V., and Botella, M. A. (2003). Developing salt tolerant plants in a new century: a molecular biology. Plant Cell 10, 101-115. doi: 10.1023/a: 1022849200433

Brand-Williams, W., Cuvelier, M. E., and Berset, C. (1995). Use of a free radical method to evaluate antioxidant activity. Lebensm.-Wiss. Technol. (Academic Press Limited) 28, 25-30. doi: 10.1016/S0023-6438(95)80008-5 physiological processes in the short term, which were maintained for 7 days under water stress, and even beyond this time given better fruit production (Penella et al., 2017). Growth preservation in plants A/A25 after PEG addition was associated with maintained $\mathrm{CO}_{2}$ assimilation and partly open stomata, which allowed water uptake and preserved RWC. The conservative water strategy involved minor oxidative stress as demonstrated by the lower $\mathrm{H}_{2} \mathrm{O}_{2}$ concentration and diminished membrane lipid peroxidation. These results could be attributed to the capacity to maintain shoot growth by the root system's conservative tolerance traits under drought stress. Consequently, the grafting of commercial cultivars onto drought-tolerant rootstock(s) such as A/A25 can be considered a valid strategy to improve drought stress tolerance. Nevertheless, other mechanisms, like the hormone signaling cascade (Cantero-Navarro et al., 2016) or the mobility of genetic components (Haroldsen et al., 2012), which were not contemplated herein, could also explain the improved drought tolerance of these grafted plants, and should be studied in future works.

\section{AUTHOR CONTRIBUTIONS}

LL-S, CP, and ÁC conceived and designed the experiments. LL-S, GC-S, GVS, CP, and ÁC performed the experiments. AS, SL-G, LL-S, and ÁC analyzed the data and discussed the results of this study. ÁC wrote the paper. All the authors read and approved the manuscript.

\section{FUNDING}

This work has funded by INIA (Spain) through Project RTA201700030-C02-00 and the European Regional Development Fund (ERDF). LL-S is a beneficiary of a doctoral fellowship (FPI-INIA).

Cantero-Navarro, E., Romero-Aranda, R., Fernández-Muñoz, R., et al. (2016). Improving agronomic water use efficiency in tomato by rootstock-mediated hormonal regulation of leaf biomass. Plant Sci. 251, 90-100. doi: 10.1016/j. plantsci.2016.03.001

Chouka, A. S., and Jebari, H. (1999). Effect of grafting on watermelon vegetative and root development, production and fruit quality. Acta Hortic. 492, 85-93. doi: 10.17660/actahortic.1999.492.10

Colla, G., Rouphael, Y., Leonardi, C., and Bie, Z. (2010). Role of grafting in vegetable crops grown under saline conditions. Sci. Hortic. 127, 147-155. doi: 10.1016/j.scienta.2010.08.004

Correia, M. J., Fonseca, F., Azedo-Silva, J., Dias, C., David, M. M., Barrote, I., et al. (2005). Effects of water deficit on the activity of nitrate reductase and content of sugars, nitrate and free amino acids in the leaves and roots of sunflower and white lupin plants growing under two nutrient supply regimes. Physiol. Planta 24, 61-70. doi: 10.1111/j.1399-3054.2005.00486.x

Cuartero, J., Bolarín, M. C., Asíns, M. J., and Moreno, V. (2006). Increasing salt tolerance in the tomato. J. Exp. Bot. 57, 1045-1058. doi: 10.1093/jxb/erj102

Delfine, S., Tognetti, R., Loreto, F., and Alvino, A. (2002). Physiological and growth responses to water stress in field-grown bell pepper (Capsicum annuum L.). J. Hortic. Sci. Biotechnol. 77, 697-704. doi: 10.1080/14620316.2002.11511559

Dhindsa, R. S., Plumb-Dhindsa, P., and Thorpe, T. A. (1981). Leaf senescence: correlated with increased levels of membrane permeability and lipid peroxidation, and decreased levels of superoxide dismutase and catalase. J. Exp. Bot. 32, 93-101. doi: 10.1093/jxb/32.1.93 
Estañ, M. T., Martinez-Rodriguez, M. M., Perez-Alfocea, F., Flowers, T. J., and Bolarin, M. C. (2005). Grafting raises the salt tolerance of tomato through limiting the transport of sodium and chloride to the shoot. J. Exp. Bot. 56, 703-712. doi: 10.1093/jxb/eri027

Fahad, S., Nazir, U., Anjum, S. A., Farooq, A., Zohaib, A., et al. (2017). Crop production under drought and heat stress: plant responses and management options. Front. Plant Sci. 8:1147. doi: 10.3389/fpls.2017.01147

Feller, U., and Vaseva, I. I. (2014). Extreme climatic events: impacts of drought and high temperature on physiological processes in agronomically important plants. Front. Plant Sci. 2:39. doi: 10.3389/fenvs.2014.00039

Ferrario, S., Valadier, M. H., Morot-Gaudry, J. F., and Foyer, C. (1995). Effects of constitutive expression of nitrate reductase in transgenic Nicotiana plumbaginifolia L. in response to varying nitrogen supply. Planta 196, 288-294. doi: $10.1007 /$ bf00201387

Finckh, M. R. (2008). "Integration of breeding and technology into diversification strategies for disease control in modern agriculture," in Sustainable Disease Management in a European Context, eds D. B. Collinge, L. Munk, and B. M. Cooke (Dordrecht: Springer), 399-409. doi: 10.1007/978-1-4020-8780-6_19

Flexas, J., Barón, M., Bota, J., Ducruet, J. M., Gallé, A., Galmé, J., et al. (2009). Photosynthesis limitations during water stress acclimation and recovery in the drought-adapted Vitis hybrid Richter-110 (V. berlandieri $\times$ V. rupestris). J. Exp. Bot. 60, 2361-2377. doi: 10.1093/jxb/erp069

Flexas, J., Bota, J., Loreto, F., Cornic, G., and Sharkey, T. D. (2004). Diffusive and metabolic limitations to photosynthesis under drought and salinity in C3 plants. Plant Biol. 6, 269-279. doi: 10.1055/s-2004-820867

García-Mata, C., and Lamattina, L. (2001). Nitric oxide induces stomatal closure and enhances the adaptive plant responses against drought stress. Plant Physiol. 126, 1196-1204. doi: 10.1104/pp.126.3.1196

García-Sánchez, F., Rubio, F., and Martínez, V. (2010). “Abiotic stresses: salinity and drought," in Agricultural Sciences: Topics in Modern Agriculture, eds A. Gonzalez-Fontes, A. Garate, and I. Bonilla (Houston, TX: Studium Press). doi: $10.5772 / 56078$

Gilliham, M., Able, J. A., and Roy, S. J. (2017). Translating knowledge about abiotic stress tolerance to breeding programmes. Plant J. 90, 898-917. doi: 10.1111/tpj. 13456

Hageman, R. H., and Hucklesby, D. P. (1971). Nitrate reductase from higher plants. Methods Enzymol. 23, 491-503. doi: 10.1016/s0076-6879(71)23121-9

Haroldsen, V. M., Szczerba, M. W., Aktas, H., Lopez-Baltazar, J., Odias, M. J., Chi-Ham, C. L., et al. (2012). Mobility of transgenic nucleic acids and proteins within grafted rootstocks for agricultural improvement. Front. Plant Sci. 3:39. doi: 10.3389/fpls.2012.00039

He, Y., Zhu, Z. J., Yang, J., Ni, X. L., and Zhu, B. (2009). Grafting increases the salt tolerance of tomato improvement of photosynthesis and enhancement of antioxidant enzymes activity. Environ. Exp. Bot. 66, 270-278. doi: 10.1016/j. envexpbot.2009.02.007

Heath, R. L., and Packer, L. (1968). Photoperoxidation in isolated chloroplasts. I. Kinetics and stoichiometry of fatty acid peroxidation. Arch. Biochem. Biophys. 125, 189-198. doi: 10.1016/0003-9861(68)90523-7

Hsiao, T. C., and Xu, L. K. (2000). Sensitivity of growth of roots versus leaves to water stress: biophysical analysis and relation to water transport. J. Exp. Bot. 51, 1595-1616. doi: 10.1093/jexbot/51.350.1595

Jaworski, E. G. (1971). Nitrate reductase assays in intact plant tissue. Biochem. Biophys. Res. Commun. 43, 1274-1279. doi: 10.1016/s0006-291x(71)80010-4

Kaiser, W. M., and Huber, S. C. (2001). Post-translational regulation of nitrate reductase: mechanism, physiological relevance and environmental triggers. J. Exp. Bot. 52, 1981-1989. doi: 10.1093/jexbot/52.363.1981

Keleş, Y., and Öncel, I. (2002). Response of antioxidative defense system to temperature and water stress combinations in wheat seed lings. Plant Sci. 163, 783-790. doi: 10.1016/s0168-9452(02)00213-3

Koç, E., and İşlek, C., and Üstün, A. S. (2010). Effect of cold on protein, proline, phenolic compounds and chlorophyll content of two pepper (Capsicum annuum L.) varieties. GU. J. Sci. 23, 1-6. doi: 10.1007/978-3-540-95991-5_14

Koevoets, I. T., Venema, J. H., Elzenga, J. T. M., and Testerink, C. (2016). Roots withstanding their environment: exploiting root system architecture responses to abiotic stress to improve crop tolerance. Front. Plant Sci. 7:1335. doi: 10.3389/ fpls.2016.01335

Kumar, P., Rouphael, Y., Cardelli, M. T., and Colla, G. (2017). Vegetable grafting as a tool to improve drought resistance and water use efficiency. Front. Plant Sci. 8:1130. doi: 10.3389/fpls.2017.01130
Kyriacou, M. C., Rouphael, Y., Colla, G., Zrenner, R., and Schwarz, D. (2017). Vegetable grafting: the implications of a growing agronomic imperative for vegetable fruit quality and nutritive value. Front. Plant Sci. 8:741. doi: 10.3389/ fpls.2017.00741

Lamaoui, M., Jemo, M., Datla, R., and Bekkaoui, F. (2018). Heat and drought stresses in crops and approaches for their mitigation. Front. Plant Sci. 6:26. doi: $10.3389 /$ fchem.2018.00026

Lammerts van Bueren, E. T., Jones, S. S., Tamm, L., Murphy, K. M., Myers, J. R., et al. (2011). The need to breed crop varieties suitable for organic farming, using wheat, tomato and broccoli as examples: a review. NJAS - Wageningen J. Life Sci. 58, 193-205. doi: 10.1016/j.njas.2010.04.001

Lee, J. M., Kubota, C., Tsao, S. J., Biel, Z., Hoyos Echevarria, P., Morra, L., et al. (2010). Current status of vegetables grafting: diffusion, grafting techniques, automation. Sci. Hortic. 127, 93-105. doi: 10.1016/j.scienta.2010.08.003

Lexa, M., and Cheeseman, J. M. (1997). Growth and nitrogen relations in reciprocal grafts of wild-type and nitrate reductase-deficient mutants of pea (Pisum sativum L. var, Juneau). J. Exp. Bot. 48, 1241-1250. doi: 10.1093/jxb/48.6.1241

Li, H., Liu, S. S., Yi, C. Y., Wang, F., Zhou, J., Xia, X.-J., et al. (2014). Hydrogen peroxide mediates abscisic acid-induced HSP70 accumulation and heat tolerance in grafted cucumber plants. Plant Cell Environ. 37, 2768-2780. doi: $10.1111 /$ pce. 12360

Lillo, C., Meyer, C., Lea, U. S., Provan, F., and Oltedal, S. (2004). Mechanism and importance of post-translational regulation of nitrate reductase. J. Exp. Bot. 55, 1275-1282. doi: 10.1093/jxb/erh132

Liu, S., Li, H., Lv, X., Ahammed, G. J., Xia, X., Zhou, J., et al. (2016). Grafting cucumber onto luffa improves drought tolerance by increasing ABA biosynthesis and sensitivity. Sci. Rep. 6:20212. doi: 10.1038/srep 20212

Loggini, B., Scartazza, A., Brugnoli, E., and Navari-Izzo, F. (1999). Antioxidant defense system, pigment composition and photosynthetic efficiency in two wheat cultivars subjected to drought. Plant Physiol. 119, 1091-1099. doi: 10. 1104/pp.119.3.1091

Martínez-Ballesta, M. C., Martínez, V., and Carvajal, M. (2004). Osmotic adjustment, water relations and gas exchange in pepper plants grown under $\mathrm{NaCl}$ or KCl. Environ. Exp. Bot. 52, 161-174. doi: 10.1016/j.envexpbot.2004. 01.012

Martínez-Rodríguez, M. M., Estañ, M. T., Moyano, E., Garcia-Abellan, J. O., Flores, F. B., Campos, J. F., et al. (2008). The effectiveness of grafting to improve salt tolerance in tomato when an "excluder" genotype is used as scion. Environ. Exp. Bot. 63, 392-401. doi: 10.1016/j.envexpbot.2007.12.007

Munns, R. (2002). Avenues for increasing salt tolerance of crops, and the role of physiologically based selection traits. Plant Soil 247, 93-105. doi: 10.1007/97894-017-2789-1_7

Navarro, J. M., Garrido, C., Martínez, V., and Carvajal, M. (2003). Water relations and xylem transport of nutrients in pepper plants grown under two different salts stress regimes. Plant Growth Regul. 41, 237-245. doi: 10.1023/B:GROW. 0000007515.72795.c5

Orsini, F., Sanoubar, R., Oztekin, G. B., Kappel, N., Tepecik, M., Quacquarelli, C., et al. (2013). Improved stomatal regulation and ion partitioning boosts salt tolerance in grafted melon. Funct. Plant Biol. 40, 628-636. doi: 10.1071/FP 12350

Penella, C., Landi, M., Guidi, L., Nebauer, S. G., Pellegrini, E., San Bautista, A., et al. (2016). Salt-tolerant rootstock increases yield of pepper under salinity through maintenance of photosynthetic performance and sinks strength. J. Plant Physiol. 193, 1-11. doi: 10.1016/j.jplph.2016.02.007

Penella, C., Nebauer, S. G., López-Galarza, S., Quiñones, A., San Bautista, A., and Calatayud, A. (2017). Grafting pepper onto tolerant rootstocks: an environmental-friendly technique overcomes water and salt stress. Sci. Hortic. 226, 33-41. doi: 10.1016/j.scienta.2017.08.020

Penella, C., Nebauer, S. G., López-Galarza, S., San Bautista, A., RodríguezBurruezo, A., and Calatayud, A. (2014a). Evaluation of some pepper genotypes as rootstocks in water stress conditions. Hortic. Sci. 41, 192-200. doi: 10.17221/ 163/2013-hortsci

Penella, C., Nebauer, S. G., San Bautista, A., López-Galarza, S., and Calatayud, A. (2014b). Rootstock alleviates PEG-induced water stress in grafted pepper seedlings: physiological responses. J. Plant Physiol. 171, 842-851. doi: 10.1016/ j.jplph.2014.01.013

Pokorny, J. (2001). "Natural antioxidant functionality during food processing," in Antioxidants in Food, Practical Applications, eds J. Pokorny, N. Yanishlieva, 
and M. Gordon (Cambridge: CRC Press, Woodhead Publishing Ltd.), 335-351.

Reddy, A. R., Chaitanya, K. V., and Vivekanandan, M. (2004). Drought-induced responses of photosynthesis and antioxidant metabolism in higher plants. J. Plant Physiol. 161, 1189-1120. doi: 10.1016/j.jplph.2004.01.013

Rivero, R. M., Ruiz, J., and Romero, L. (2003a). Role of grafting in horticultural plants under stress conditions. Food Agric. Environ. 1, 70-74. doi: 10.1002/jsfa. 1541

Rivero, R. M., Ruiz, J. M., Sánchez, E., and Romero, L. (2003b). Does grafting provide tomato plants an advantage against $\mathrm{H} 2 \mathrm{O} 2$ production under conditions of thermal shock? Physiol. Planta 117, 44-50. doi: 10.1034/j.1399-3054.2003. 1170105.x

Rouphael, Y., Cardarelli, M., and Colla, G. (2008). Yield, mineral composition, water relations and water use efficiency of grafted mini-watermelon plants under deficit irrigation. HortScience 43, 730-736. doi: 10.1080/14620316.2006. 11512041

Sade, N., Gebremedhin, A., and Moshelion, M. (2012). Risk-taking plants. Anisohydric behavior as a stress-resistance trait. Plant Sig. Behav. 7, 767-770. doi: $10.4161 /$ psb.20505

Sairam, R. K., and Srivastava, G. C. (2001). Water stress tolerance of wheat (Triticum aestivum L.): variations in hydrogen peroxide accumulation and antioxidant activity in tolerant and susceptible genotypes. J. Agron. Crop Sci. 186, 63-70. doi: 10.1046/j.1439-037x.2001.00461.x

Sánchez-Rodríguez, E., Leyva, R., Constán-Aguilar, C., Romero, L., and Ruiz, J. M. (2014). How does grafting affect the ionome of cherry tomato plants under water stress? Soil Sci. Plant Nutr. 60, 145-155. doi: 10.1080/00380768.2013. 870873

Sánchez-Rodríguez, E., Romero, L., and Ruiz, J. M. (2013). Role of grafting in resistance to water stress in tomato plants: ammonia production and assimilation. J. Plant Growth Regul. 32, 831-842. doi: 10.1007/s00344-0139348-2

Sánchez-Rodríguez, E., Rubio-Wilhelmi, M. M., Blasco, B., Leyva, R., Romero, L., and Ruiz, J. M. (2012). Antioxidant response resides in the shoot in reciprocal grafts of drought tolerant and drought-sensitive cultivars in tomato under water stress. Plant Sci. 188, 89-96. doi: 10.1016/j.plantsci.2011.12.019

Savvas, D., Colla, G., Rouphael, Y., and Schwarz, D. (2010). Amelioration of heavy metal and nutrient stress in fruit vegetables by grafting. Sci. Hortic. 127, 156-161. doi: 10.1016/j.scienta.2010.09.011

Savvas, D., Savvas, A., Ntatsi, G., Ropokis, A., Karapanos, I., Krumbein, A., et al. (2011). Effects of three comercial rootstocks on mineral nutrition, fruit yield, and quality of salinized tomato. J. Plant Nutr. Soil Sci. 174, 154-162. doi: $10.1002 /$ jpln.201000099

Scheurwater, I., Koren, M., Lambers, H., and Atkin, O. K. (2002). The contribution of roots and shoots to whole plant nitrate reduction in fast- and slow-growing grass species. J. Exp. Bot. 53, 1635-1642. doi: 10.1093/jxb/erf008

Schwarz, D., Rouphael, Y., Colla, G., and Venema, J. H. (2010). Grafting as a tool to improve tolerance of vegetables to abiotic stresses: thermal stress, water stress and organic pollutants. Sci. Hortic. 127, 162-171. doi: 10.1016/j.scienta.2010 09.016

Sergiev, I., Alexieva, V., and Karanov, E. (1997). Effect of spermine, atrazine and combination between them on some endogenous protective systems and stress markers in plants. Compt. Rend. Acad. Bulg. Sci. 51, $121-124$.

Sharp, R. E., Wu, Y., Voetberg, G. S., Saab, I. N., and LeNoble, M. E. (1994). Confirmation that abscisic acid accumulation is required for maize primary root elongation at low water potentials. J. Exp. Bot. 45, 1734-1751. doi: 10.1093/jxb/ 45.special_issue.1743

Silva, C., Martínez, V., and Carvajal, M. (2008). Osmotic versus toxic effects of $\mathrm{NaCl}$ on pepper plants. Biol. Planta 52, 72-79. doi: 10.1007/s10535-008-0010-y

Tardieu, F., and Simonneau, T. (1998). Variability among species of stomatal control under fluctuating soil water status and evaporative demand: modelling isohydric and anisohydric behaviours. J. Exp. Bot. 49, 419-432. doi: 10.1093/ jexbot/49.suppl_1.419

Urban, L., Aarrouf, J., and Bidel, L. P. R. (2017). Assessing the effects of water deficit on photosynthesis using parameters derived from measurements of leaf gas exchange and of chlorophyll a fluorescence. Front. Plant Sci. 8:2068. doi: 10.3389/fpls.2017.02068

Velikova, V. I, Yordanov, I., and Edreva, A. (2000). Oxidative stress and some antioxidant systems in acid rain-treated bean plants protective role of exogenous polyamines. Plant Sci. 151, 59-66. doi: 10.1016/s0168-9452(99) 00197-1

Westgate, M. E., and Boyer, J. S. (1985). Osmotic adjustment and the inhibition of leaf, root, stem and silk growth at low water potentials in maize. Planta 164, 540-549. doi: 10.1007/bf00395973

Yao, X., Yang, R., Zhao, F., Wang, S., Li, C., and Zhao, W. (2016). An analysis of physiological index of differences in drought tolerance of tomato rootstock seedlings. J. Plant Biol. 59, 311-321. doi: 10.1007/s12374-0160071-y

Yousfi, S., Serret, M. D., Márquez, A. J., Voltas, J., and Araus, J. L. (2012). Combined use of $\delta 13 \mathrm{C}, \delta 18 \mathrm{O}$ and $\delta 15 \mathrm{~N}$ tracks nitrogen metabolism and genotypic adaptation of durum wheat to salinity and water deficit. New Phytol. 194, 230-244. doi: 10.1111/j.1469-8137.2011.04036.x

Conflict of Interest Statement: The authors declare that the research was conducted in the absence of any commercial or financial relationships that could be construed as a potential conflict of interest.

Copyright (๔ 2019 López-Serrano, Canet-Sanchis, Vuletin Selak, Penella, San Bautista, López-Galarza and Calatayud. This is an open-access article distributed under the terms of the Creative Commons Attribution License (CC BY). The use, distribution or reproduction in other forums is permitted, provided the original author(s) and the copyright owner(s) are credited and that the original publication in this journal is cited, in accordance with accepted academic practice. No use, distribution or reproduction is permitted which does not comply with these terms. 